\title{
EFFECTS OF TRYPTOPHAN SUPPLEMENTATION ON AGGRESSION AMONG GROUP-HOUSED GESTATING SOWS ${ }^{1}$
}

\author{
Y.Z. Li*, S.K. Baidoo ${ }^{\#}$, L.J. Johnston*, and J.E. Anderson ${ }^{\S}$ \\ *West Central Research and Outreach Center, University of Minnesota, Morris \\ ${ }^{\text {\#}}$ Southern Research and Outreach Center, University of Minnesota, Waseca \\ ${ }^{\S}$ Division of Science and Mathematics, University of Minnesota, Morris
}

The objective of this study was to determine effects of dietary tryptophan (Trp) supplementation on mixing-induced aggression and the associated stress, and reproductive performance in gestating sows. Sows were mixed after weaning in pens with electronic sow feeders on concrete partially-slatted floors. Each pen housed $21 \pm 3$ sows, with approximately 2.5 square feet per sow of floor space allowance excluding the feeder station. Multiparous sows $(n=168)$ from 8 breeding groups were used, with 4 groups assigned to the control diet, and 4 groups assigned to the high Trp diet. Control sows received corn-soybean meal based diets throughout gestation $(0.15 \% \operatorname{Trp})$ and lactation $(0.21 \% \operatorname{Trp})$. Sows assigned to high Trp received about two times the dietary $\operatorname{Trp}(0.35 \%$ in gestation diet and $0.48 \%$ in lactation diet) fed to control sows $3 \mathrm{~d}$ before and after mixing. Six focal sows (2 sows from each of parity 1,2, and 3 or greater) in each pen were designated and videotaped after mixing for 72 hours to determine the type and number of aggressive interactions among sows. Before and 48 hours after mixing, saliva samples were collected from focal sows, and scratches were assessed on all sows. Data were analyzed using the Frequency and Glimmix procedures of SAS. Aggression among sows was intense during the initial 6 hours, and decreased dramatically between 6 to 72 hours after grouping. The initial aggression caused scratches and elevated cortisol concentrations $(P<0.05)$. Mature sows fought for longer periods ( $\left.116 \mathrm{vs} .52 \mathrm{sec} \cdot \mathrm{h}^{-1} \cdot \mathrm{sow}^{-1}, \mathrm{SE}=20.1 ; P<0.05\right)$, but had fewer scratches caused by aggression (injury score $=4.6$ vs. $6.8, \mathrm{SE}=1.13 ; P<0.05$ ) than parity 1 sows. Supplementation of dietary $\operatorname{Trp}$ did not affect aggressive behaviors. Consequently, there was no difference in injury scores or saliva cortisol concentrations between dietary treatments. High Trp sows had more total piglets born (12.6 vs. $10.5 \mathrm{pigs} / \mathrm{litter}, \mathrm{SE}=0.54 ; P<0.01)$, and more piglets born alive (10.9 vs. 9.7 pigs/litter, $\mathrm{SE}=0.44 ; P<0.05)$ at farrowing than control sows. The results indicate that the initial aggression caused more injuries in young sows than in mature sows. Supplementation of dietary Trp at twice the control level for a short period did not effectively reduce aggression and the associated stress in sows at grouping.

Key words: aggression, gestating sows, group-housing, tryptophan.

${ }^{1}$ Acknowledgement: The authors greatly appreciated the financial support of the Minnesota Pork Board and the Pork Checkoff for this research project. Appreciation also goes to David and Karen Richter for providing the farm site, facilities and animals for this study. 